\title{
CERVICAL VAGAL SCHWANNOMA- A RARE DIFFERENTIAL DIAGNOSIS OF BENIGN SOLID NECK MASS
}

Bikram Haldar1, Sahid Khondaker2, Bitan Kumar Chattopadhyay³

1 Postgraduate Trainee, Department of General Surgery, IPGME and R, Kolkata.

2 Postgraduate Trainee, Department of General Surgery, IPGME and R, Kolkata.

3 Professor and HOD, Department of General Surgery, IPGME and R, Kolkata.

HOW TO CITE THIS ARTICLE: Haldar B, Khondaker S, Chattopadhyay BK. Cervical vagal schwannoma- a rare differential diagnosis of benign solid neck mass. J. Evolution Med. Dent. Sci. 2018;7(05):702-704, DOI: 10.14260/jemds/2018/159

\section{PRESENTATION OF CASE}

A 52-year-old female patient presented with a swelling in the right upper aspect of her neck for the last 16 years. Rapid increase in size since last 5 months, associated with pain on palpation only with no radiation or referral pain. Not associated with dysphagia, dyspnoea, otalgia or hoarseness of voice. A single swelling of $8 * 5 \mathrm{~cm}$ was seen over the right upper part of neck in the anterior triangle. It was extending from $2 \mathrm{~cm}$ below the ear lobule up to the lower third of sternocleidomastoid muscle.

Medially, it was extending $1 \mathrm{~cm}$ away from the midline, having smooth surface and distinct margins. It was firm on palpation and had some mobility in the transverse axis. Overlying skin was normal. Visible transmitted pulsations were seen (Fig. 1). Carotid pulsations could be felt at the upper border of the mass.

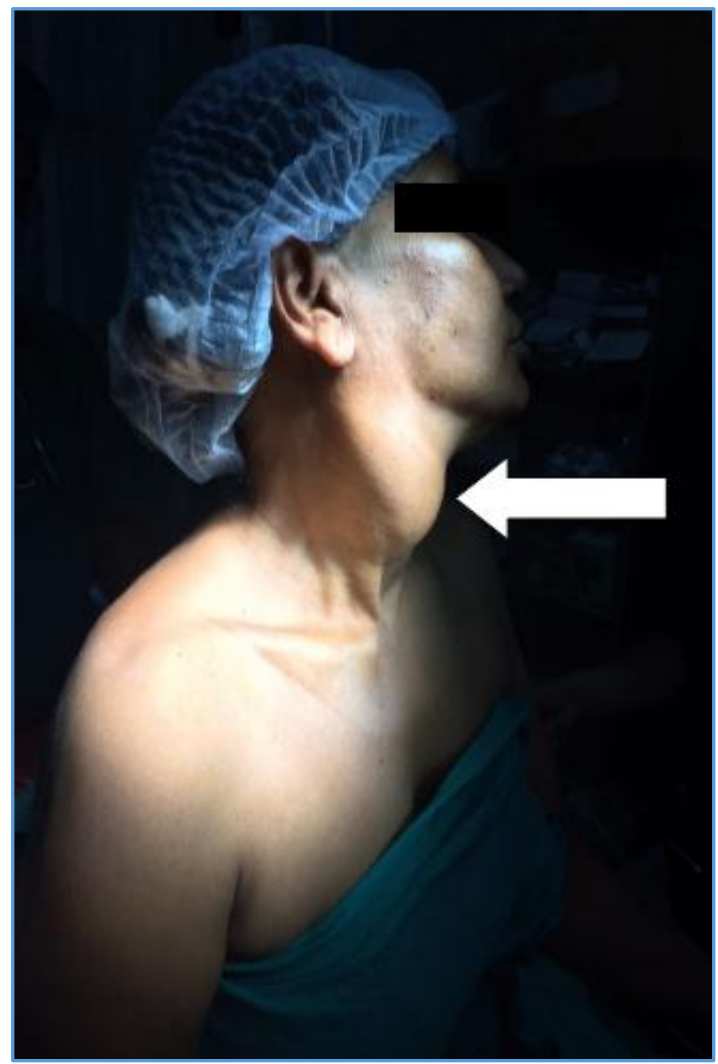

Figure 1. Clinical Photograph showing the Right Lateral Neck Mass

'Financial or Other Competing Interest': None.

Submission 19-12-2017, Peer Review 12-01-2018,

Acceptance 18-01-2018, Published 29-01-2018.

Corresponding Author:

Dr. Bikram Haldar,

\#1C1-25/5, Pranyik Housing Complex,

Thakurpukur, Kolkata-700104.

E-mail: Bikramhaldar6883@gmail.com

DOI: $10.14260 /$ jemds/2018/159

(c) (i) $(9)$
Routine investigations were within normal limits. USG neck with colour Doppler revealed a well-circumscribed, heterogeneous mass. The carotid artery was significantly displaced due to the compression of the mass lesion.

CT scan and Magnetic Resonance Imaging (MRI) of the neck confirmed a $7 \times 4 \times 3.5 \mathrm{~cm}$ mass in the carotid space with high signal intensity on T1-weighted MRI and heterogeneous higher signal intensity on T2-weighted MRI (Fig. 2, 3).

The lesion showed irregular peripheral enhancement with displacement of the internal jugular vein and the common carotid artery.

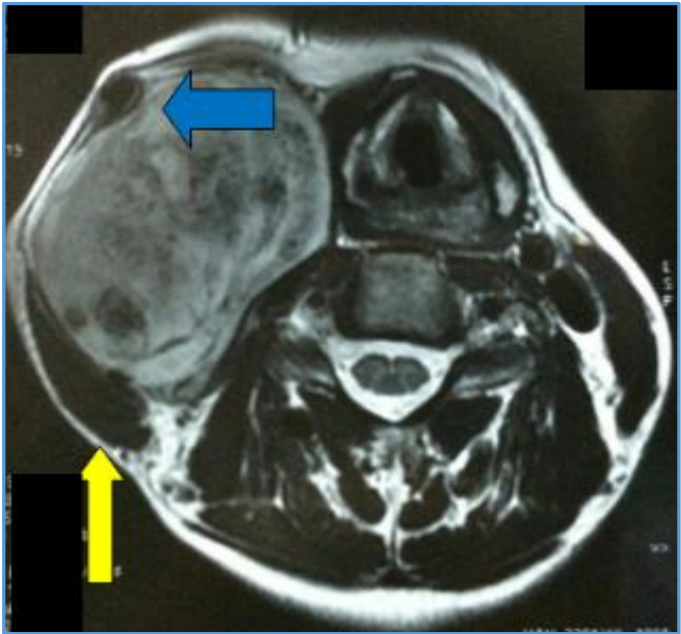

Figure 2. MRI Scan showing a Right Lateral Neck Mass Displacing the Common Carotid Artery Anteriorly (Blue Arrow) and Pushing the Sternocleidomastoid Muscle and Internal Jugular Vein Posterolaterally (Yellow Arrow)

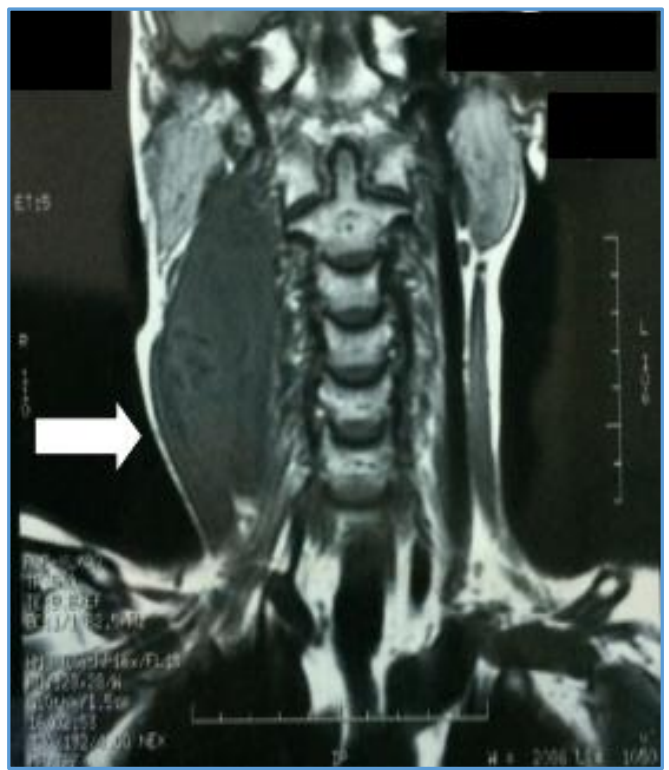

Figure 3. MRI Scan showing the Lateral Neck Mass and its Extent 


\section{DIFFERENTIAL DIAGNOSES}

The differential diagnoses of the case were-

a) Branchial cyst.

b) Neurofibroma.

c) Reactive lymphadenitis.

d) Carotid body tumour.

e) Paraganglioma.

f) Lateral aberrant thyroid.

\section{CLINICAL DIAGNOSIS}

The clinical diagnosis of the case was a nerve sheath tumour arising in the carotid triangle.

\section{DISCUSSION OF MANAGEMENT}

An oblique skin incision made over the sternocleidomastoid muscle extending from upper third up to the junction of middle and lower third.

A yellowish mass encapsulated by the carotid sheath was seen displacing the common carotid artery medially (Fig. 4). Internal jugular vein was seen displaced laterally underneath the sternocleidomastoid muscle.

Carotid sheath was opened. Sternocleidomastoid muscle was divided to improve access. Mass was well encapsulated with no adhesions and was delivered outside.

Upper extension was seen till the bifurcation of the common carotid artery and the mass was seen to arise from the right vagus nerve.

It was evident by the presence of a pedicled stalk. It was divided and the nerve was preserved (Fig. 5, 6). Postoperative period was uneventful and was not associated with any neuro deficit.

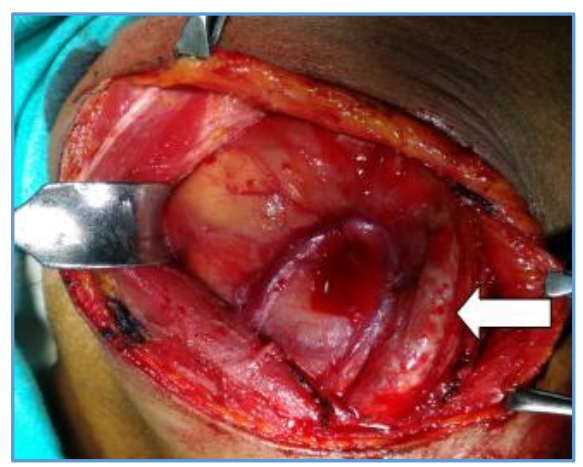

Figure 4. Intraoperative Picture showing the Yellowish Mass which is Displacing the Common Carotid Artery Antero-Medially

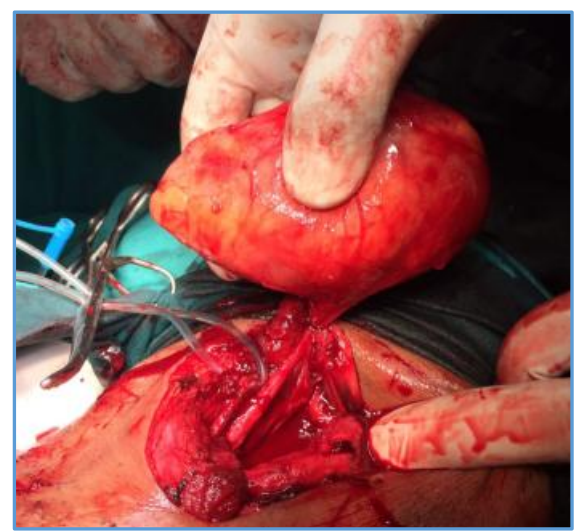

Figure 5. Intraoperative Picture showing the Pedicle of the Mass Originating from the Right Vagus Nerve

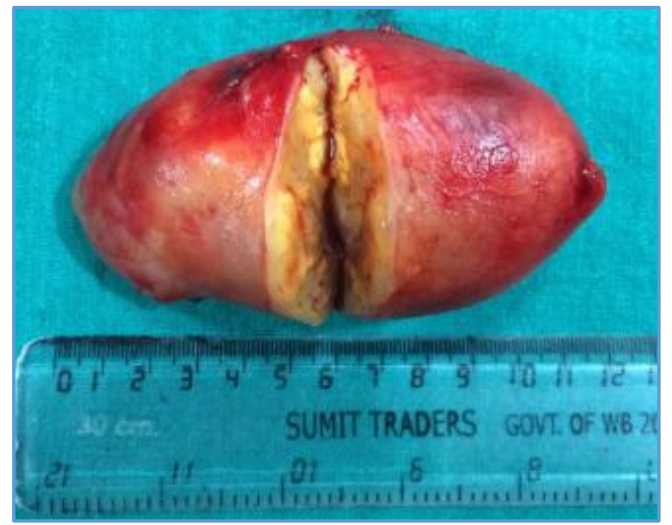

Figure 6. Picture of the Specimen with Cut Surface showing Yellowish Fleshy Appearance

\section{PATHOLOGICAL DISCUSSION}

On histopathological examination, the tumour was found to be composed of characteristic Verocay bodies and focal hypercellular (Anthony A) and hypocellular areas (Anthony B). The findings were suggestive of a schwannoma (Fig. 7).

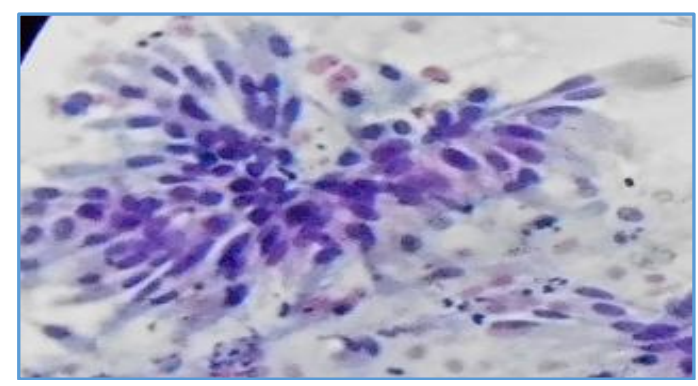

Figure 7. Histopathological Examination showing Hypercellularity with Verocay Bodies

\section{DISCUSSION}

Schwannomas, also known as neurilemmomas, neuromas or neurinomas are uncommon nerve sheath neoplasms that may arise from any peripheral, cranial or autonomic nerve of the body with the exception of the optic nerve.

Schwannomas developing from the cranial nerves most commonly affect the vestibulocochlear nerve, rarely the glossopharyngeal, accessory and the hypoglossal nerves. ${ }^{1}$ The involvement of vagus nerve has been reported in about $10 \%$ of the cases. ${ }^{2}$

Neoplasms of the vagus nerve includes Paragangliomas (50\%), schwannomas (31\%), neurofibromas (14\%) and neurofibrosarcomas $(4 \%){ }^{3}$

It is seen commonly in middle aged males, but may occur in females too. Preoperative diagnosis is often difficult as vagal schwannoma generally do not present with neurological deficits.

Hoarseness of voice is often seen and a paroxysmal cough on palpation of the mass may be used as a clinical indicator of vagal nerve involvement. ${ }^{4}$ Diagnosis of vagal schwannoma by preoperative FNAC is mostly inconclusive.

MRI and CT scan help in determining the tumour location in between the carotid artery and internal jugular vein, tumour size and relationship to surrounding structures. Specific findings on MRI scans like split fat sign, fascicular sign, target sign and signal patterns like isointense T1 signal relative to skeletal muscle, increased and slightly 
heterogeneous T2 signal help in further specifying the lesion. ${ }^{5}$

Adequate treatment involves complete removal of the lesion, while safeguarding the nerve involved.

Kang et al reported that more than half of the surgically treated cases exhibited postoperative neurological deficits that were primarily caused by iatrogenic injury to the nerve of origin or adjacent nerve endings. ${ }^{1}$

An attentive surgical technique with minimal use of energy sources and careful dissection of the fascicles of the nerve prevents unwanted neural compromise.

The malignant potential and the risk of recurrences are still under evaluation. ${ }^{6} \mathrm{~A}$ complete surgical excision has the least chance of recurrence. ${ }^{1,7}$

It appears as a yellowish white well circumscribed mass. Cytological diagnosis of schwannoma is based on observation of Verocay bodies and spindle cells. On histopathological examination there are two main patterns; Anthony A and Anthony B. Anthony A areas are composed of compact spindle cells with indistinct cytoplasmic borders and Anthony $B$ areas are areas of looser Schwann cell proliferation.5,7

Schwannomas have been commonly associated with Neurofibromatosis type 2 . When multiple schwannomas are present without any other stigmata of neurofibromatosis, then it can be defined as schwannomatosis. ${ }^{8}$

\section{FINAL DIAGNOSIS}

A vagal schwannoma was the final diagnosis of the case.

\section{REFERENCES}

[1] Kang GC, Soo KC, Lim DT. Extracranial non-vestibular head and neck schwannomas: a ten-year experience. Annals of the Academy of Medicine Singapore 2007;36(4):233-40.

[2] Leu YS, Chang KC. Extracranial head and neck schwannomas: a review of 8 years experience. Acta Otolaryngol 2002;122(4):435-7.

[3] Green JD, Olsen KD, DeSanto LW, et al. Neoplasms of the vagus nerve. Laryngoscope 1988;98(6 Pt 1):64854 .

[4] Ford LC, Cruz RM, Rumore GJ, et al. Cervical cystic schwannoma of the vagus nerve: diagnostic and surgical challenge. J Otolaryngol 2003;32(1):61-3.

[5] Beaman FD, Kransdorf MJ, Menke DM. Schwannoma: radiologic-pathologic correlation. Radiographics 2004;24(5):1477-81.

[6] Langner E, Del Negro A, Akashi HK, et al. Schwannomas in the head and neck: retrospective analysis of 21 patients and review of the literature. Sao Paulo Med J 2007;125(4):220-2.

[7] Biswas D, Marnane CN, Mal R, et al. Extracranial head and neck schwannomas-a 10-year review. Auris Nasus Larynx 2007;34(3):353-9.

[8] Seppala MT, Saino MA, Haltia MJ, et al. Multiple schwannomas: schwannomatosis or neurofibromatosis type 2? Journal of Neurosurgery 1998;89(1):36-41. 